\title{
Effectiveness of passive seismic control of steel structures
}

\author{
O. Prodan, I. Ladar \& P. Alexa \\ Technical University, Cluj-Napoca, Romania
}

\begin{abstract}
This paper introduces a simple approach in assessing the amount of seismic mitigation of passive seismic protection of steel skeletal type structures. The amount of seismic protection is expressed in terms of reduction in the amplitudes of kinematical parameters associated to seismically induced oscillatory motion of the analyzed structures. The introduced parameter for assessing seismic protection is associated to the mitigation interval of steel skeletal structures equipped with passive protection. This interval is expressed in terms of natural vibration periods of the structure and is considered from the moment when the vibratory motion is initiated until the moment the motion reaches its steady state. During this time interval, a clear picture of vibratory motion is exhibited: length of the interval, number of vibratory cycles, amplitudes, their variation/decrease in time, the end of transitory motion and the beginning of the (short, nevertheless) pseudo - steady state motion.

The paper proposes a time variable parameter that synthesizes all these features of the transitory motion. The length of this interval and its descending slope emphasize the effectiveness of seismic protection. The shorter the interval and the greater its descending slope, the more effective the associated seismic protection.

Time history type analyses have been carried out on several sets of skeletal steel structures. The structures are analyzed in two situations: without seismic protection (reference structure) and equipped with passive seismic protection (viscous dampers). The numerical results of time history analyses are presented and discussed with reference to the proposed parameter assessing seismic mitigation. The time variation of the proposed parameter is presented graphically for a better and immediate "physical" perception. The effectiveness of the seismic passive protection is discussed in terms of proposed parameter.
\end{abstract}

Keywords: steel structures, dampers, time history analysis, mitigation curves. 


\section{Introduction}

A reduced seismic response to an input earthquake associated to location area is the simplest way to define the objective of seismic protection of structures. Reduction of seismic response has to be expressed in various parameters, both static and kinematical. Although, in structural design, it is both customary and code provided to subject a structure to a statically applied equivalent loading, the efficiency of seismic protection is more relevant when it is presented in terms of reduction in the peak values of induced kinematical parameters, mainly in terms of lateral top displacements (as is the case of a multi-storey structure). Indeed, what else other than a dramatic reduction in the top lateral displacements of a skeletal structure induced by a strong earthquake may better symbolize a seismic protection system? Earthquake induced kinematical parameters associated to top structural levels are both very popular in being connected to seismic protection and, also, very versatile in presenting the level of seismic protectiveness in a comparative manner (e.g. Constantinou [1], Chopra [2], Soong [3]). Nevertheless, it is important to point out that a passive seismic protection via viscous dampers will result in visible change (decrease) in lateral displacements, while the changes (reductions) in accelerations are not significant.

From the point of view of seismically induced kinematical parameters (displacements, velocities, accelerations), seismic behaviour of frame type steel structures exhibits three distinct intervals:

- A first, starting ascending interval during which the seismic induced kinematics increase (in both their positive and negative values). Depending on the specific input accelerogram, this interval is associated with rapidly increasing values of lateral displacements directly related to the mechanical inertia of the structure.

- A second interval is associated with the large (including peak values) input accelerogram. During this interval, the structure develops large oscillatory values of its static and kinematical states. The large values of displacements and stresses induce in their turn damages in skeletal structures: cracks, formation of plastic zones, yielding in tensioned steel, buckling of compressed members, etc. If the earthquake is strong enough, a shakedown type behaviour is probably reached.

- A third, ending interval may be related with a reduction in acceleration values down to their complete diminishing. The structure is either saved by dramatic decreases in the values of its static and kinematical states, or collapses.

A seismic efficient protection is achieved if it operates during the second interval by reducing both its lengths and values of corresponding parameters (displacements, velocities, accelerations). An efficient seismic protection system, fully operating in this interval, will save the structural damages by avoiding the shakedown type behaviour and starting a progressive descending behaviour. The more rapidly the mitigation interval is initiated and the steeper its form, the more seismically efficient the protection system. The present paper focuses on the 
versatility of the envelop curves that collect the peak values of kinematical parameters to express the efficiency of seismic protection. The envelop curves are referred to as "seismic protection efficiency curves" (SPEC).

The present study deals with computing, assessing and comparing the efficiency of passive seismic protection via viscous elastic dampers from the point of view of this mitigation interval via seismic protection efficiency curves. The study has been conducted on a large set of steel skeletal structures designed for office buildings located in an area of Romania known for its high seismic potential. Out of a larger set of studied structures, a six story five bay frame has been selected and associated to the below presented numerical results. The structure is acted upon by the Vrancea 1977 Romania recorded earthquake accelerogram (a reference accelerogram) and, also, by a sinusoidal accelerogram. The latter has been used in order to prevent the mitigation effect associated with the decrease in the values of a natural accelerogram. Both the Vrancea and the sinusoidal accelerograms are applied on the structure acted upon by dead and live loadings (design code combination) associated to office building serviceability.

A reference seismically unprotected frame and three alternatives (of viscous damping levels) of seismic protection are analysed. The seismic protection consists of nine viscous dampers, placed in the central bay along the entire height of the structure. The three alternatives of seismic protection are approximately equivalent to a general inherent damping level of $10 \%, 15 \%$ and $20 \%$, respectively.

Performed analyses are of time-history type. Computed parameters are lateral top displacements with a special focus on the form (length and reduction in values) of the mitigation interval. The graphical representation of the mitigation effect - through seismic protection efficiency curves (SPEC) of seismic protection has been considered more approachable for those interested. A special issue related to the mitigation interval is the amount of reduction in (usually) peak values of computed kinematical parameter. Also, a question arises: when and in what conditions may an oscillatory motion, that is irrefutably transitory (due to the transitory feature of the earthquake), may be considered a steady state motion? This question is responsible for introducing - in the present study - a sinusoidal type accelerogram. By exhibiting an indefinite steady state characteristic, a sinusoidal accelerogram can be associated to a real steady state motion induced into the analysed structure. Under a sinusoidal type action, the mitigation interval and the steady state motion can be clearly defined. A real seismic accelerogram will, only, display a pseudo steady state motion.

\section{Analysed structures}

The general and sectional geometry of both, reference (unequipped) frame see Fig. 1 and equipped frames e.g. see Fig. 2 are the same. The cross sections of columns and beams of the reference frame (Fig. 1) have been computed from a loading combination that includes seismic action according to current Romanian design provisions for steel structures. A general stress state of approximately 
$75 \%$ of full (bending) capacity of the frame members is reached and associated to the elements cross sections. The sections of elements, also, observe design provisions with reference to local stability and deformation state. A deep study, of the influence of dampers location in the frame, lead to the present placement: in the central bay along the entire height of the structure (Fig. 2).

The intensity of sinusoidal accelerogram (Fig. 4) has been fixed at $0.2 \mathrm{~g}$, corresponding to the maximum value of recorded Vrancea N-S (March 1977) accelerogram (Fig. 3). Vrancea 1977 earthquake exhibited a 7.2 magnitude on Richter scale (maximum predicted magnitude is 7.5) and lasted 50 seconds approximately. By its destructions and casualties, Vrancea 1977 earthquake is considered a reference earthquake in this country.

Regarding the aspect about global level of damping induced into the structure via viscous dampers, it has been dealt with by using seismic response displacement code spectra for several levels of damping (e.g. Constantinou [4]). Induced level of damping has been equated to the damping level of code displacement spectra when producing the same displacements. In this way, a natural (inherent) level of 5\% and three artificially induced levels (via viscous dampers) of damping of approximately $10 \%, 15 \%$ and $20 \%$ respectively have been taken into account in the performed analyses.

The dampers (of FIP INDUSTRIALE type) are of nonlinear viscous type: the damping force is given as $\mathrm{F}_{\mathrm{a}}=\mathrm{c}^{*} \mathrm{v}^{0.15}$ (e.g. Baldo [5]). Here, $\mathrm{c}$ is an adaptable

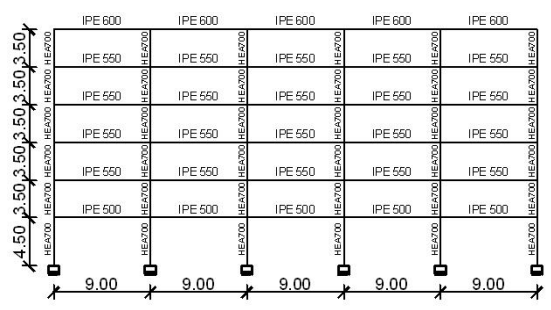

Figure 1: Reference frame.

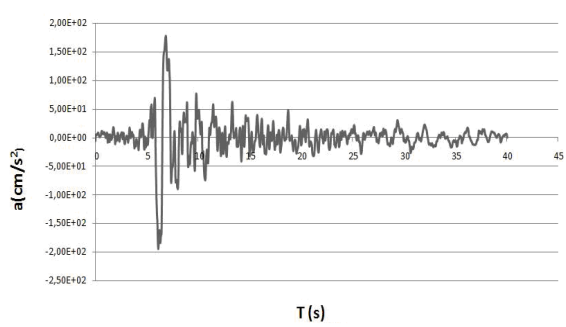

Figure 3: Vrancea 1977 accelerogram.

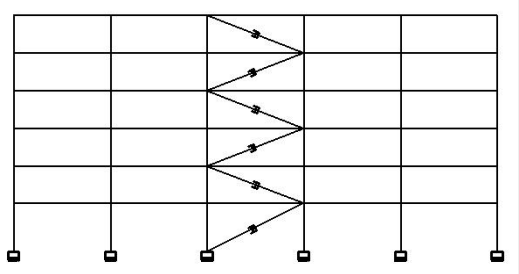

Figure 2: Frame with viscous dampers.

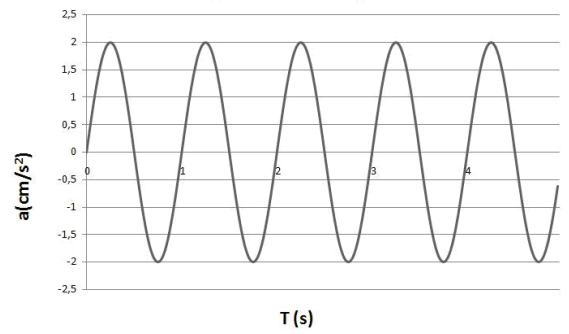

Figure 4: Sinusoidal accelerogram. 
damping coefficient (and its values have been computed for each global damping level) and $\mathrm{v}$ is velocity of motion and it is implicitly computed.

\section{Numerical results}

As it has been mentioned, the focus of this paper is especially on the mitigation interval of lateral top displacements graphically expressed by seismic protection efficiency curves (SPEC's). In the case of recorded Vrancea 1977 accelerogram, as well as in the case of the sinusoidal type accelerogram, the displacements versus time presented diagrams have been extracted from the entire diagram (associated to the real duration of earthquake, approximately 55 seconds), such that "extracted segments" comprise the mitigation intervals. Such a "zoom" of the mitigation interval allows a better assessment of the length and slope of SPEC's. The computed numerical results associated to the three cases of supplemental damping are presented versus the homologous results related to the reference structure.

With the aim of exhibiting the efficiency of seismic protection via viscous dampers and the global level of damping, the seismic protection efficiency curves (SPEC's) have been computed as envelope of peak (positive and negative) values of displacement versus time diagrams. Indeed, the steepness of these envelope curves expresses both, the length (in time) of the mitigation interval and the amount of reduction in the peak values of the kinematical parameters (displacements, in this case).

A steady state motion is considered when the reduction in the displacements values reaches approximately $70 \%$ of their maximum values. Presented numerical results refer to displacements variation with time of top lateral displacement in the case of Vrancea earthquake (Fig. 3) for the reference frame and three levels of supplemental damping: 10\% (Fig. 5), reference frame and 15\% supplemental damping (Fig. 6) and reference frame and 20\% supplemental damping (Fig. 7). In the case of sinusoidal accelerogram, similar results are presented: reference frame and 10\% supplemental damping (Fig. 8) reference frame and 15\% supplemental damping (Fig. 9) and reference frame and 20\% supplemental damping (Fig. 10), respectively. Corresponding seismic mitigation curves (SPEC's) for above study cases are presented in Fig. 11, Fig 12 and Fig. 13 - for Vrancea 1977 earthquake and in Fig. 14, Fig. 15 and Fig. 16, respectively - for sinusoidal type excitation.

To exhibit the amount of reduction in the peak values of displacements, the time (horizontal) axis is, also, scaled in terms of fundamental natural period $\mathrm{T}_{1}$ of analyzed structure. Expressing the seismic mitigation interval in terms of (fundamental) natural period of the structure allows for emphasise of the efficiency of seismic protection (level of supplemental damping). The proposed seismic protection efficiency curves (SPEC's) underline - by their slope - the duration and rapidity of the seismic mitigation in terms of the natural fundamental periods of vibration of analysed structure. 


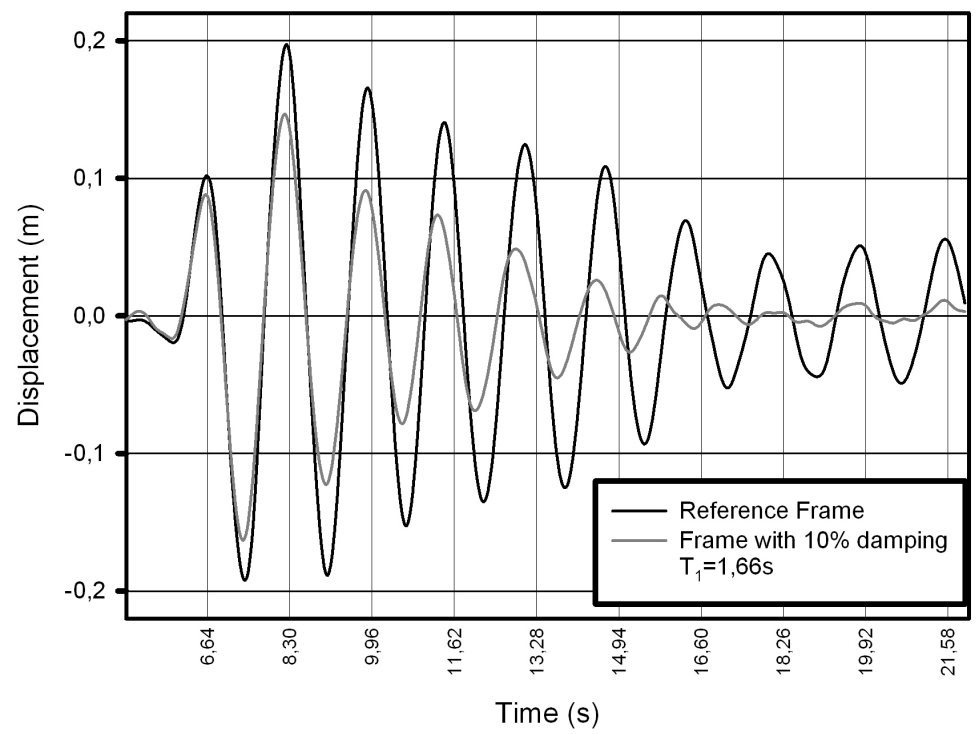

Figure 5: Displacements - reference frame versus frame with $10 \%$ damping (VRANCEA).

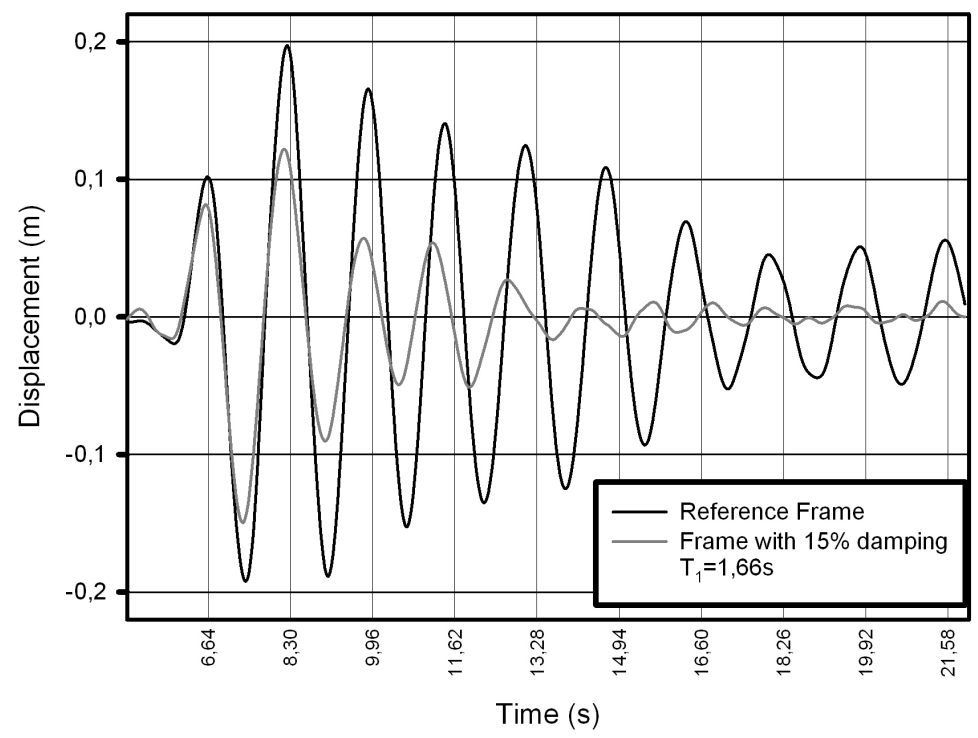

Figure 6: Displacements - reference frame versus frame with $15 \%$ damping (VRANCEA). 


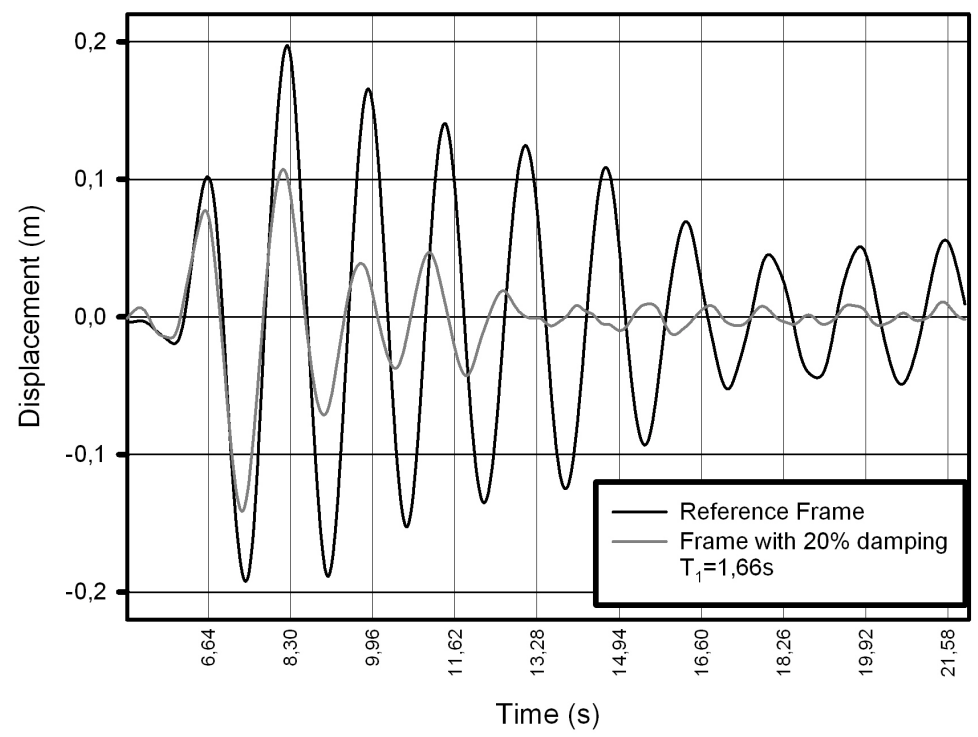

Figure 7: Displacements - reference frame versus frame with $20 \%$ damping (VRANCEA).

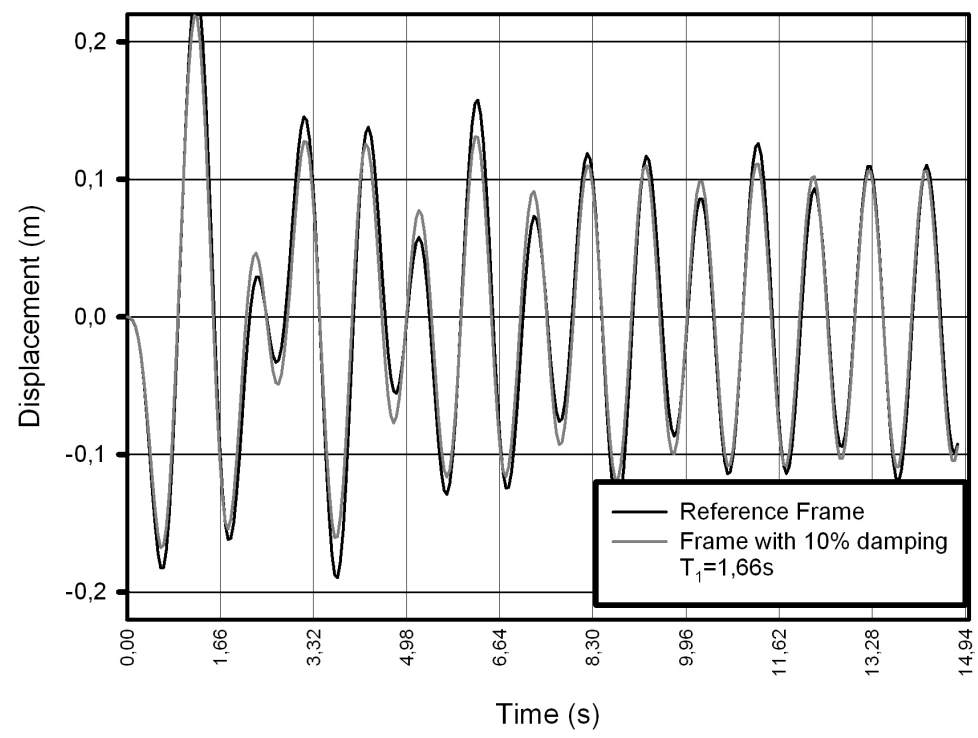

Figure 8: Displacements - reference frame versus frame with 10\% damping (Sinusoidal). 


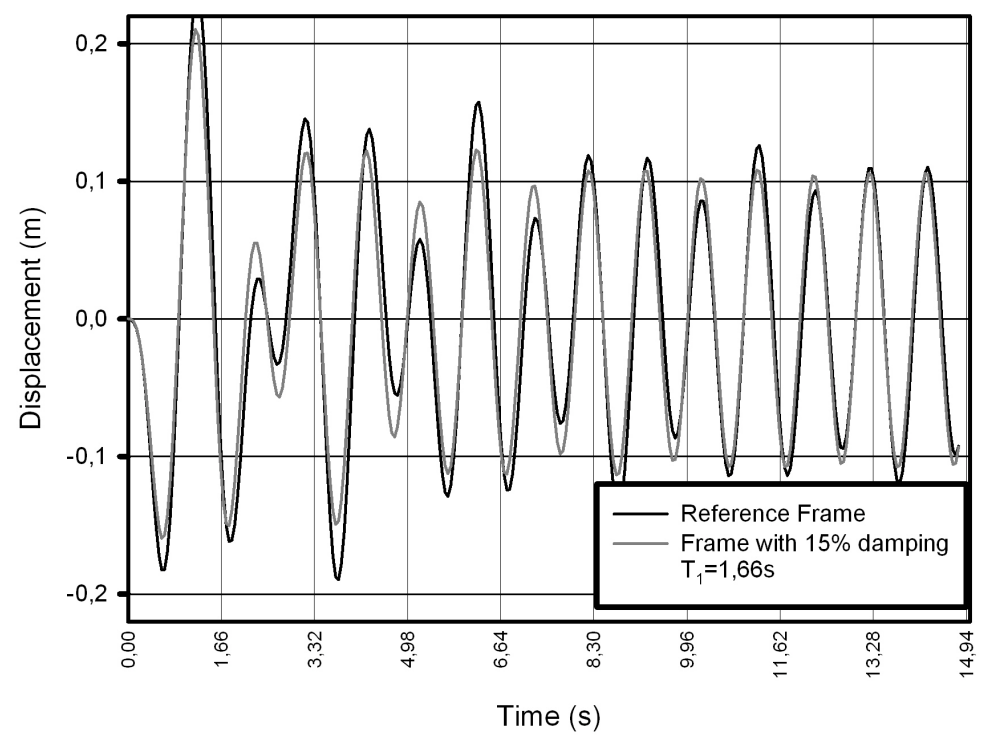

Figure 9: Displacements - reference frame versus frame with 15\% damping (Sinusoidal).

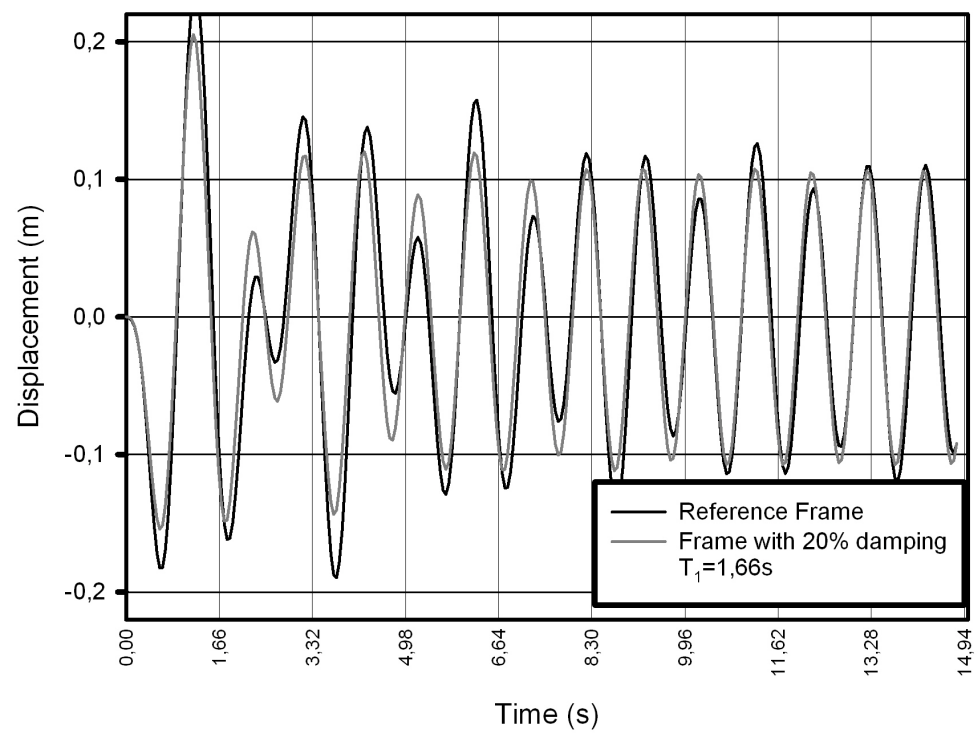

Figure 10: Displacements - reference frame versus frame with 20\% damping (Sinusoidal). 


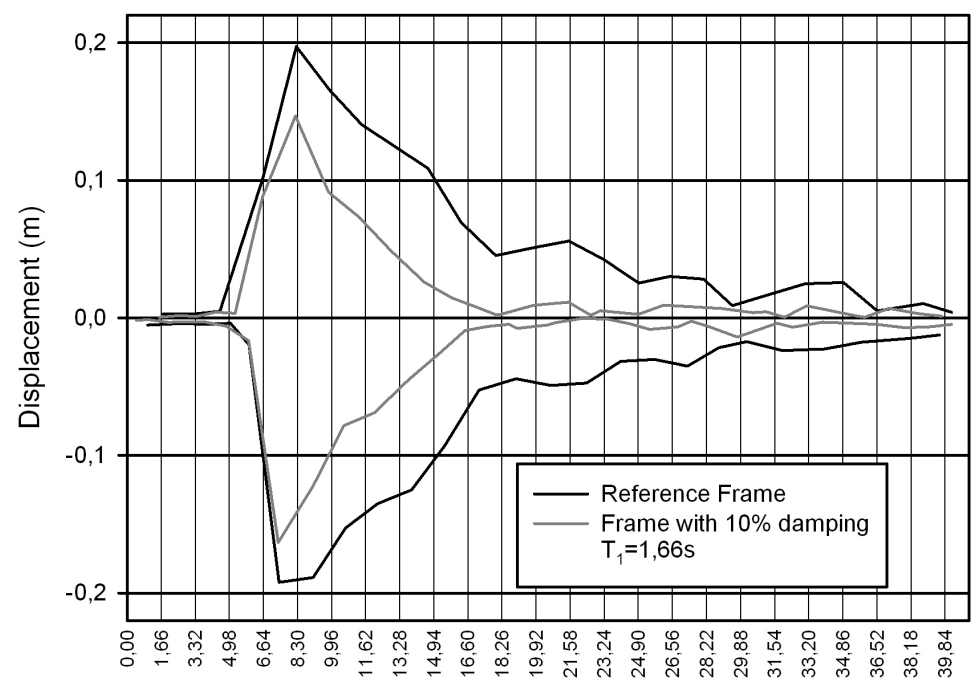

Time (s)

Figure 11: Displacement mitigation curves - reference frame versus frame with $10 \%$ damping (VRANCEA).

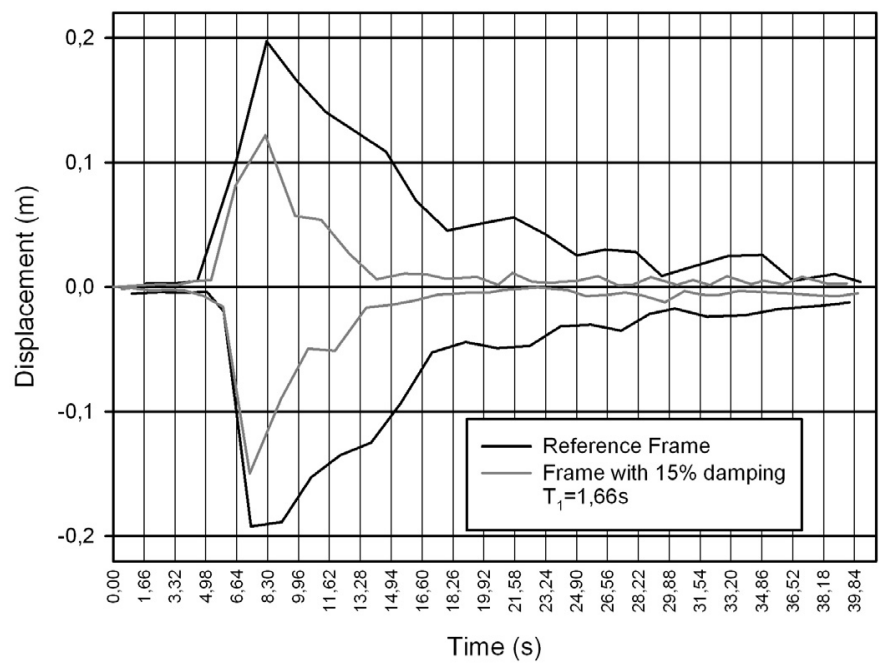

Figure 12: Displacement mitigation curves - reference frame versus frame with $15 \%$ damping (VRANCEA). 


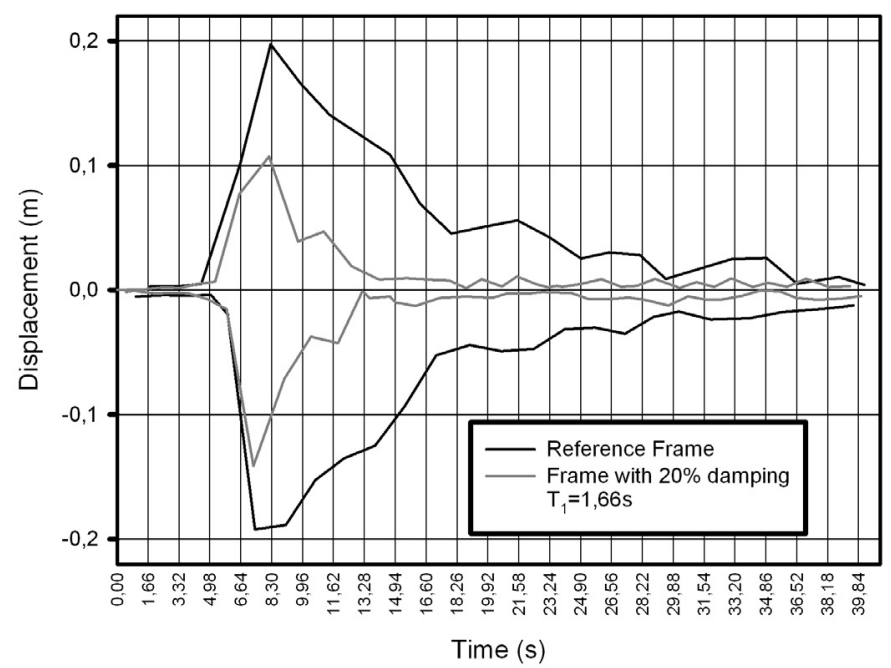

Figure 13: Displacement mitigation curves - reference frame versus frame with $20 \%$ damping (VRANCEA).

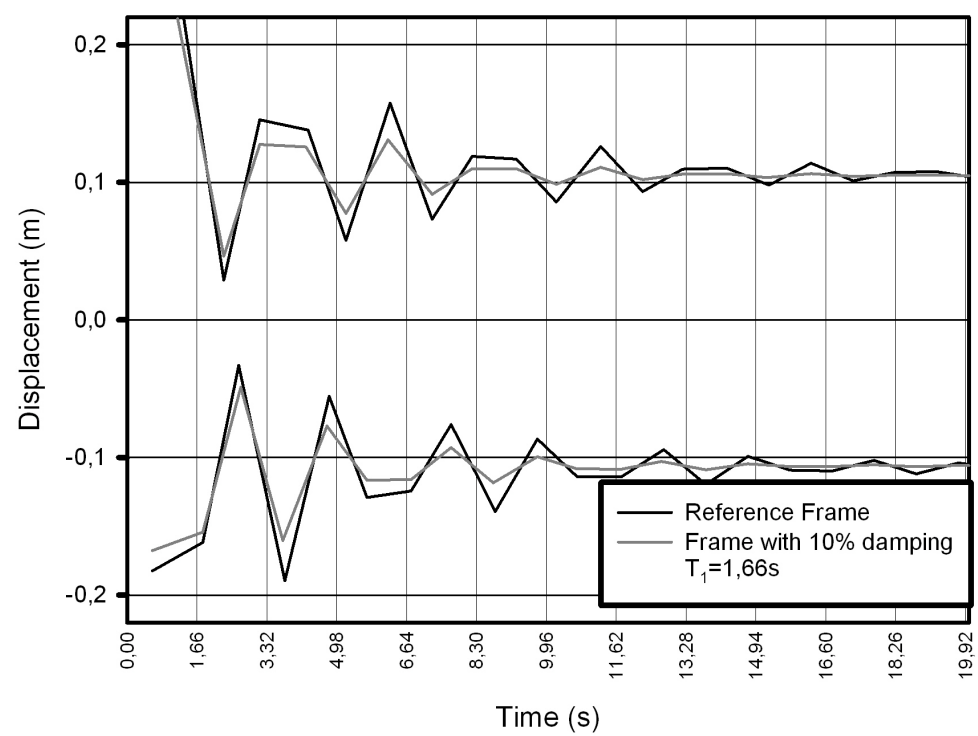

Figure 14: Displacement mitigation curves - reference frame versus frame with $10 \%$ damping (sinusoidal). 


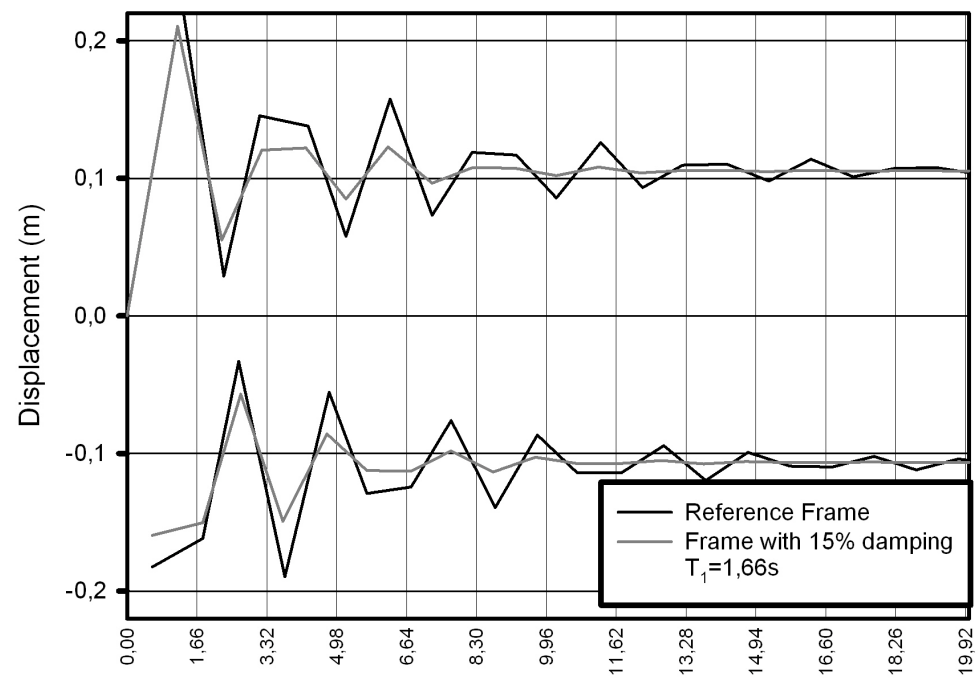

Time (s)

Figure 15: Displacement mitigation curves - reference frame versus frame with $15 \%$ damping (sinusoidal).

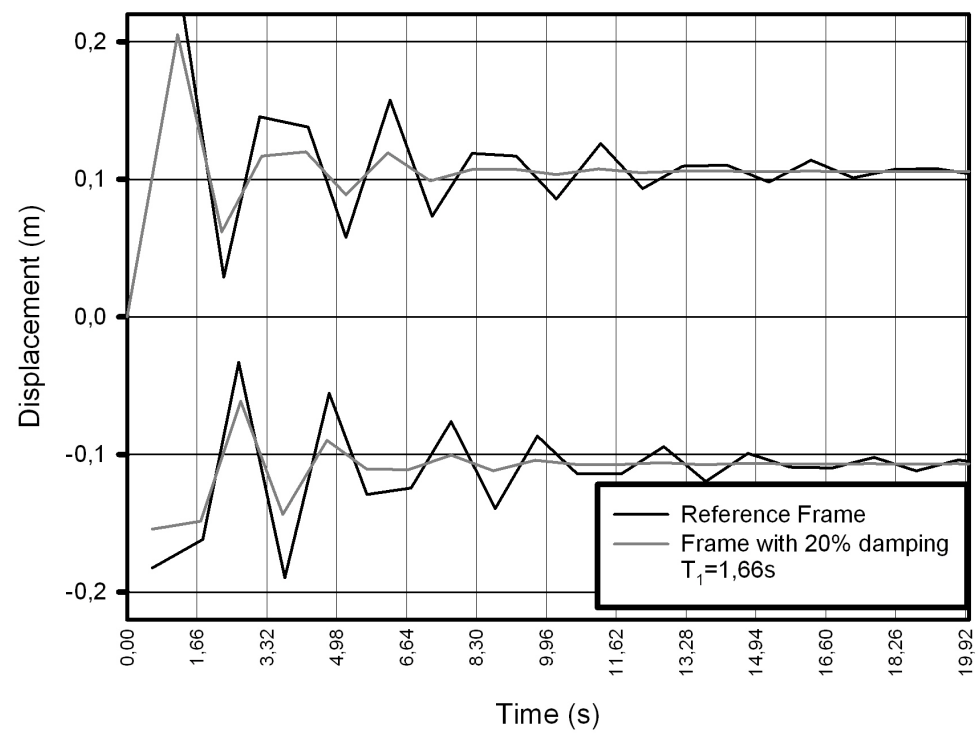

Figure 16: Displacement mitigation curves - reference frame versus frame with $20 \%$ damping (sinusoidal). 


\section{Conclusions}

The final conclusions refer to the efficiency of the seismic protection via viscous dampers and, mainly, to the proposed assessment of this efficiency via mitigation envelope curve (SPEC). An inherent (e.g. de Silva [6]) damping level of 5\% is considered as a standard unit of damping level. Therefore, a damping level of $15 \%$, for instance, is referred to as a 3 unit level, while a $20 \%$ damping level will be a 4 unit level.

It may be concluded that a doubling in the damping level (from standard 5\% to 2 unit level of $10 \%$ ) results in a reduction in top lateral displacements of $15 \%$, while a threefold increase induces a decrease of $26 \%$ in lateral top displacements. The (20\%) level of damping is equivalent to a reduction of $33 \%$ (in the case of Vrancea accelerogram) and of $18 \%, 27 \%$ and $32 \%$, respectively (in the case of sinusoidal excitation). The mitigation envelope curves (SPEC's) are eloquent in terms of the length of the interval expressed in the natural fundamental period. In the case of reference frame, the length of the mitigation interval (extending from $\mathrm{t}=3 \mathrm{~T}_{1}$ to $\mathrm{t}=10 \mathrm{~T}_{1}$ ) is reduced from $7 \mathrm{~T}_{1}$ to $4.5 \mathrm{~T}_{1}$ in the case of $10 \%$ added damping and Vrancea accelerogram, e.g. see Fig. 11. Similarly, SPEC's associated to $15 \%$ and $20 \%$ levels of added damping and sinusoidal excitation are presented e.g. see Fig. 12 to Fig. 16.

The proposed mitigation enveloped curves (SPEC's) prove to be a versatile tool of assessing the efficiency of supplemental damping. Their expressing in terms of fundamental natural period of the structure allows a rapid and synthetic evaluation of supplemental damping efficiency. A vibration "stage" along a time interval up to two fundamental periods $\left(2 \mathrm{~T}_{1}\right)$ may save the structure of shakedown behaviour and, consequently, of remanent deformations. Also, the decrease in the values of top lateral displacements offers immediate asses of the measure of reductions in these values. The versatility of mitigation envelope curves and their synthetic feature opens the possibility of incorporating them in the set of performance criteria of seismically protected steel structures.

\section{References}

[1] Constantinou, M.C. and Symans, M.D. (1993). Experimental study of seismic response of buildings with supplemental fluid dampers. Structural design of tall buildings. Vol II,93-132.

[2] Chopra, A.K. (1995). Dynamics of Structures. Theory and Applications to Earthquake Engineering, Prentice Hall International, Inc.

[3] Soong, T.T. and Dargush G.F. (1997). Passive Energy Dissipation Systems in Structural Engineering, Wiley, Chichester - England

[4] Constantinou, M.C. (2007). Fluid dampers for applications of energy dissipation and seismic isolation.

[5] Baldo, P., Tomaselli, F. and Pimenta, F. (2004). Loureiro viaduct seismic protection: Testing of non-linear viscous dampers. SEISMICA 2004 Congresso Nacional de Sismologia e Engenharia Sismica, 679-690

[6] de Silva, C.W. (2007). Vibration Damping, Control, and Design, CRC Press 